\title{
ANALISIS VALUASI SAHAM PT. SEMEN INDONESIA (PERSERO) TBK DENGAN METODE DISCOUNTED CASH FLOW (DCF)
}

\author{
Dina Yeni Martia, Wiwik Setyawati, Fitri Khaerunisa, Yuli Hastuti \\ Politeknik Negeri Semarang, Jl. Prof. Soedharto SH Tembalang Semarang \\ 50277 \\ *Corresponding Author: dinamartia8@gmail.com
}

\begin{abstract}
As an investors should be able to consider and conduct an assessment of shares that can provide optimal returns in making investment decisions. Assessment can be done by analyzing the fairness of stock price of the company. This study aims to determine the stock price of PT. Semen Indonesia of the period 2014-2016. The method used in this research is fundamental analysis using Discounted Cash Flow (DCF) approach. The result of this study shows that PT. Semen Indonesia's stock is in an undervalued condition. Therefore, the right decision for the investor is to buy the stock for investment or not to sell the stock in the hope that in the future the stock price will rise.
\end{abstract}

Keywords: stocks, fundamental analysis, discounted cash flow

\begin{abstract}
Abstrak: Sebagai seorang investor harus dapat mempertimbangkan dan melakukan penilaian terhadap saham yang dapat memberikan keuntungan yang optimal dalam melakukan keputusan investasi. Penilaian dapat dilakukan dengan menganalisa kewajaran harga saham perusahaan. Penelitian ini bertujuan untuk mengetahui harga wajar saham PT. Semen Indonesia (Persero) periode tahun 2014-2016. Metode yang digunakan dalam penelitian ini yaitu analisis fundamental dengan menggunakan pendekatan Discounted Cash Flow (DCF). Hasil penelitian ini menunjukkan bahwa saham PT. Semen (Persero) Indonesia berada dalam kondisi yang undervalued sehingga keputusan yang tepat adalah membeli saham tersebut untuk investasi atau tidak menjual saham tersebut dengan harapan dikemudian hari harga saham akan naik.
\end{abstract}

Kata Kunci: saham, analisis fundamental, discounted cash flow 


\section{PENDAHULUAN}

Perkembangan ekonomi global saat ini terus mengalami pertumbuhan. Pertkembangan ini diikuti dengan semakin membaiknya kondisi pasar modal. Hal ini ditandai dengan meningkatnya antusias investor dalam negeri untuk berinvestasi di pasar modal. Sehingga pasar modal indonesia tak lagi banyak didominasi oleh investor asing.

Salah satu instrumen yang diminati oleh investor dalam pasar modal adalah saham. Menurut Tjiptono Darmaji dan Hendi M Fakhrudin $\quad(2006: 178)$ saham merupakan tanda atau pemilikan seseorang atau badan dalam suatu perusahaan atau perseroan terbatas. Sehingga apabila seseorang atau badan memiliki saham suatu perusahaan, dapat dikatan bahwa seseorang atau badan tersebut ikut memiki perusahaan tersebut. Sahamsaham yang listing di BEI dikelompokkan menjadi beberapa sektor. Salah satu sub sektor yang terdaftar di bei adalah sub sektor semen dimana perusahaanperusahaan yang listing di subsektor ini bisnis utamanya adalah menghasilkan semen.

Berdasarkan data Global Cement Report pada tahun 2015, Indonesia merupakan negara yang menduduki peringkat ke-10 sebagai produsen semen terbesar di dunia dan merupakan negara eksportir kedua setelah Saudi Arabia. Negara yang menjadi tujuan ekspor semen dari Indonesia beberapa diantaranya adalah Australia, Bangladesh, Filipina, Sri Lanka, Timor Leste, Maladewa, dan beberapa negara di Afrika.

Kementerian Perindustrian (KEMENPERIN), menyebutkan bahwa kebutuhan semen nasional 70 juta ton per tahun, sementara total kapasitas semen nasional akan mencapai 102 ton pada tahun 2017 . Namun, produksi semen nasionalsaat ini hanya mencapai 68,7 ton dengan kemampuan produksi 59,85 juta ton. Hal ini menunjukkan bahwa kebutuhan akan semen masih sangat besar mengingat gencarnya pemerintah membangun infrastruktur. Semen merupakan salah satu bahan yang sangat dibutuhkan dalam pembangunan infratsruktur. Baik untuk membangun jalan, jembatan maupun gedung. Selain itu, kelas menengah yang berkembang yang memunculkan pembangunan perumahan dan real estat baru. Sehingga tren peningkatan kebutuhan semen diperkirakan akan terus berlanjut.

Salah satu perusahaan semen yang tercatat di BEI adalah PT Semen Indonesia Tbk. Perusahaan ini memiliki beberapa anak perusahaan, diantaranya adalah Semen Gresik, Semen Padang dan Semen Tonasa. PT Semen Indonesia juga melakukan akuisisi terhadap lebih dari satu perusahaan di bidang bisnis yang sama. PT Semen Indonesia Tbk merupakan perusahaan semen terbesar di Indonesia, dengan penguasaan pangsa pasar sebesar $42 \%$ PT Semen Indonesia Tbk merupakan salah satu perusahaan semen yang patut diperhitungkan.

Risiko berinvestasi di pasar modal, terutama saham sangat tinggi. Hal ini karena saham memiliki karakteristik high risk high return, yaitu semakin tinggi risiko semakin tinggi pula return yang bisa didapatkan. Sehingga investor harus hati-hati saat berinvestasi saham. Agar mendapat return yang besar namun risiko bisa dikendalikan dengan baik.

Oleh karena itu, investor perlu melakukan analisis sebelum memutuskan untuk membeli saham. Salah satu analisis yang dapat digunakan adalah analisis valuasi saham yang dapat digunakan untuk mengetahui apakah harga saham yang ditawarkan terlalu tinggi (overvalued) atau terlalu rendah (undervalued).

Penelitian ini bertujuan untuk mengetahui apakah harga saham PT. Semen Indonesia (Persero) berada dalam kondisi undervalued, overvalued atau wajar, dengan 
mengestimasi nilai intrinsik saham PT Semen Indonesia (Persero) Tbk dan membandingkannya dengan harga saham perusahaan di pasar.

\section{Gambaran Umum PT Semen Indonesia (Persero) Tbk \\ PT Semen Indonesia (Persero) Tbk, merupakan perusahaan} persemenan terbesar di Indonesia dan tercatat sebagai Badan Usaha Milik Negara (BUMN) pertama yang telah go regional. Melanjutkan kiprahnya dalam mendukung pembangunan bangsa, PT Semen Indonesia (Persero) Tbk kini semakin intens mengembangkan produk hilir semen, memperluas cakupan pasar dan memastikan kecukupan pasokan produksi dengan mulai membangun tambahan 2 pabrik semen baru dan menyelesaikan 1 grinding plant, menyusul telah masuknya ke tahap commissioning 2 pabrik barunya yang berlokasi di Padang dan Rembang.

PT Semen Indonesia (Persero) Tbk, sebelumnya bernama PT Semen Gresik (Persero) Tbk. merupakan perusahaan yang bergerak di bidang industri semen. Diresmikan di Gresik pada tanggal 7 Agustus 1957 oleh Presiden RI pertama dengan kapasitas terpasang 250.000 ton semen per tahun. Saham Perseroan telah tercatat di Bursa Efek Jakarta, melalui IPO yang dilaksanakan pada tanggal 8 Juli 1991 dengan kode perdagangan saham: SMGR.

Keunggulan jaringan distribusi PT Semen Indonesia (Persero) Tbk didukung oleh 30 unit gudang penyangga, pengoperasian 24 packing plant di lokasi yang strategis serta didukung oleh 243 distributor nasional untuk menjamin kelancaran pasokan semen ke seluruh penjuru Nusantara. Adapun distributor TLCC di Vietnam berjumlah 36 yang tersebar di Vietnam Utara, Tengah, dan Selatan.

Bahan Baku Area-area tambang PT Semen Indonesia (Persero) Tbk memiliki cadangan bahan baku dengan kualitas terbaik dan dalam jumlah besar, sehingga menjamin kelangsungan produksi semen di seluruh pabrik Perseroan dalam jangka panjang.

Brand Image PT Semen Indonesia (Persero) Tbk memiliki tiga merk yang lekat di hati konsumen. Pangsa pasar domestik (Indonesia) terbesar, mencapai sekitar 41,7\%, menunjukkan keunggulan reputasi yang mencerminkan kekuatan corporate dan brand image Perseroan.

\section{METODE PENELITIAN}

Jenis penelitian ini adalah penelitian deskriptif dengan pendekatan kuantitatif. Penelitian ini bertujuan memberikan gambaran kepada pembaca dan mengungkapkan fakta secara lebih mendalam. Focus dari penelitian ini yaitu untuk mengevaluasi dan menilai saham PT. Semen Indonesia (Persero).

Sumber informasi dalam penelitian ini berupa data sekunder yang diperoleh dari website PT. Semen Indonesia (Persero) dengan alamat website www.semenindonesia.com, dan website Bursa Efek Indonesia, yang berupa Laporan Keuangan Tahunan Audited dan Company Report. S. Sedangkan data-data penunjang lainnya diperoleh dari www.indonesia-investments.com serta publikasi lainnya.

Jenis data yang digunakan dalam penelitian ini yaitu data kuantitatif berupa data laporan keuangan. Laporan keuangan PT. Semen Indonesia (Persero) yang digunakan dalam penelitian ini yaitu laporan keuangan tahunan audited dan company report dari periode 2014 sampai dengan 2016.

\section{Metode Penilaian}

Metode Discounted Cash Flows (DCF) adalah metode valuasi saham yang menggunakan konsep Time Value of Money. Metode ini memperhitungkan seluruh arus uang yang mengalir di perusahaan, yaitu dividen dan laba perusahaan. Teori yang mendasari metode ini adalah seluruh uang yang mengalir di perusahaan di masa depan (future value). 
Tahap-tahap melakukan valuasi saham menggunakan DCF dengan mengadopsi teknik Charles S. Mizrahi dalam bukunya Getting Started in Value Investing, dengan sedikit modifikasi.

a. Peroleh Data Dividen, EPS dan DER

Peroleh data dividen, EPS, dan DER dari perusahaan yang ingin divaluasi. Data tersebut dari laporan keuangan perusahaan. Disarankan untuk menggunakan data minimal 5 tahun kebelakang untuk hasil valuasi yang akurat. Namun dalam penelitian ini, peneliti menggunakan 3 tahun kebelakang.

b. Hitung Rata-rata DPR, EPS Growth dan PER

Berdasarkan data yang telah diperoleh, selanjutnya dapat diperoleh data DPR (Dividen Payout Ratio, yang diperoleh dari hasil membagi Dividen dengan EPS), rata-rata tingkat pertumbuhan EPS (EPS growth) dan rata-rata PER.

c. Hitung Future Value EPS

Selanjutnya proyeksikan EPS 3 tahun kedepan.

d. Hitung Future Value Harga Saham

Proyeksi harga saham di akhir 3 tahun kedepan dapat dihitung dengan cara mengalikan Future Value EPS dengan rata-rata PER.

$$
\begin{array}{cc}
\text { PER = } & \text { Harga } \\
\text { Saham }: \text { EPS } & \\
\text { Harga Saham } & =\text { EPS } \\
\text { x PER } &
\end{array}
$$

e. Hitung Akumulasi Dividen

Langkah berikutnya adalah menghitung akumulasi dividen yang diterima selama 5 tahun kedepan. Dividen dihitung dengan mengalikan Future Value EPS dengan DPR.

f. Hitung Future Value Total

Future Value harga saham total diperoleh dengan menjumlahkan harga saham di akhir tahun ke 3 di masa depan dengan akumulasi dividen selama 3 tahun tersebut.

g. Tentukan Tingkat Imbal Hasil / Diskonto

Asumsikan imbal hasil sebesar 15\%.

h. Hitung Present Value (Harga Wajar)

Langkah terakhir adalah menghitung harga wajar saham dengan mencari Present Value dari harga saham total di masa depan dengan menggunakan rumus:

$$
\mathrm{PV}=\mathrm{FV} /(1+\mathrm{r})^{\mathrm{n}}
$$

Dimana:

$$
\begin{array}{ll}
\text { PV } & =\text { Present Value } \\
\text { FV } & =\text { Future Value } \\
\mathrm{r} & =\text { tingkat imbal hasil } \\
\mathrm{n} & =\text { tahun ke }
\end{array}
$$

\section{HASIL PENELITIAN}

Rata-rata DPR, EPS, dan PER

Tabel 1 Hasil perhitungan Rata-rata DPR, EPS Growth dan PER

\begin{tabular}{|l|l|l|l|l|l|}
\hline $\begin{array}{l}\text { Tahun } \\
\text { Dividen }\end{array}$ & Deviden & EPS & $\begin{array}{l}\text { Pertumbuhan } \\
\text { EPS(\%) }\end{array}$ & $\begin{array}{l}\text { DPR } \\
(\%)\end{array}$ & PER \\
\hline 2014 & 375,34 & 938,35 & & 40,00 & 17,63 \\
\hline 2015 & 304,91 & 762,28 & $-18,76$ & 40,00 & 14,96 \\
\hline 2016 & 304,92 & 762,30 & 0 & 40,00 & 13,94 \\
\hline rata2 & 340,13 & 850,32 & $-9,38$ & 40,00 & 15,51 \\
\hline
\end{tabular}

Sumber: hasil perhitungan

Berdasarkan perhitungan di atas dapat diketahui bahwa pertumbuhan EPS PT Semen Indonesia (Persero) sebesar -9,38\% sehingga menurut versi Mizrahi dalam Desmond Wira (2017:144) jika pertumbuhan EPS kurang dari 0,15 digunakan angka 10\% atau 0,1. Selain itu didapat pula nilai rata-rata Dividen Payout Ratio (DPR) sebesar $40,00 \%$ dan rata-rata PER sebesar 15,51 kali.

Setelah mengetahui pertumbuhan EPS, rata-rata DPR dan rata-rata PER, selanjutnya adalah 
memproyeksikan EPS sampai tiga tahun ke depan.

Tabel 2 Hasil Perhitungan Future Value EPS

\begin{tabular}{|l|l|l|}
\hline Tahun & Proyeksi EPS \\
\hline Tahun 1 (2017) & $762,30 \times(1+0,1)=$ & 838,53 \\
\hline Tahun 2 (2018) & $838,53 \times(1+0,1)=$ & 922,38 \\
\hline Tahun 3 2019$)$ & $922,38 \times(1+0,1)=$ & 1014,62 \\
\hline
\end{tabular}

Sumber: hasil perhitungan

Berdasarkan Tabel 2 , EPS pada akhir tahun ke 3 yang akan datang diketahui adalah sebesar $\mathrm{Rp}$ 1.014,62.

Future Value Harga Saham

$$
\begin{array}{ll}
\text { PER }= & \frac{\text { Harga Saham }}{\text { EPS }} \\
\text { Harga Saham }= & \text { EPS x PER } \\
= & 1.014,62 \times 15,51 \\
= & 15.736,73
\end{array}
$$

Tabel 4 Hasil Perhitungan Akumulasi Dividen

\begin{tabular}{|l|l|l|l|}
\hline Tahun & Proyeksi EPS & Dividen & 335,41 \\
\hline Tahun 1 & 838,53 & $832,53 \times 0,40=$ & 368,95 \\
\hline Tahun 2 & 922,38 & $922,38 \times 0,40=$ & 405,85 \\
\hline Tahun 3 & $1.014,62$ & $1.014,62 \times 0,40=$ & $1.110,21$ \\
\hline \multicolumn{4}{|l}{ Total }
\end{tabular}

Sumber: hasil perhitungan

Berdasarkan tabel 4 dapat diketahui bahwa jumlah dividen yang diterima selama 3 tahun ke depan adalah sebesar Rp 1.1110,21.

\section{Future Value Total}

FV Harga Saham Total $=$ Rp 15.736,73

$+\operatorname{Rp} 1.1110,21=$ Rp16.846,94

Present Value (Harga Wajar)

$$
\begin{aligned}
& \mathrm{PV} \quad=\frac{F V}{(1+r)^{n}} \\
& \text { Harga Wajar }=\frac{\operatorname{Rp} 16.846,94}{(1+0,15)^{3}} \\
& =\quad \mathrm{Rp} \quad 11.077,13 \\
& \text { (dibulatkan menjadi } \mathrm{Rp} \\
& \text { 11.077,00) }
\end{aligned}
$$

Berdasarkan perhitungan tersebut dapat diketahui bahwa nilai wajar saham PT. Semen Indonesia (Persero) atau SMGR adalah sebesar Rp11.077,00. Sedangkan harga penutupan pada tanggal 17 November 2017 adalah sebesar $R p$ 9.950,00, sehingga dapat dikatakan bahwa saham PT. Semen Indonesia (Persero) sedang berada pada posisi undervalued
Jadi pada akhir tahun ke 3 yang akan datang, saham SMGR diperkirakan akan diperdagangkan pada harga Rp15.736,73

Akumulasi Deviden

Dividen dihitung dengan mengalikan Future Value EPS dengan DPR, seperti terlihat pada table 4 .

dengan harga wajar saham yang lebih tinggi daripada harga pasar saat ini.

\section{KESIMPULAN}

Berdasarkan hasil penelitian dapat disimpulkan bahwa saham PT. Semen Indonesia (Persero) sedang berada pada posisi undervalued dengan harga wajar saham (Rp. 11.077,-) yang lebih tinggi daripada harga pasar saat ini (Rp. 9.950,-- pada harga penutupan per 17 November 2017).

\section{SARAN}

Pada penelitian ini hanya menggunakan metode Discounted Cash Flow sehingga untuk penelitian selanjutnya disarankan untuk menggunakan metode lain seperti metode Price Earning Ratio dan Price Book Value Ratio agar dapat melengkapi penelitian ini. Dari hasil penelitian ini juga disarankan bagi calon investor yang berminat 
berinvestasi saham PT. Semen Indonesia (Persero) untuk mengambil langkah membeli, dan bagi investor yang telah memiliki saham PT. Semen Indonesia sebaiknya mempertahankan saham perusahaan tersebut dan atau membeli lagi.

\section{DAFTAR PUSTAKA}

Darmaji, Tjiptono dan Hendy M. Fakhrudin. 2011, Pasar Modal di Indonesia. Edisi 3. Jakarta: Salemba Empat

Sunariyah, 2006. Pengantar Pengetahuan Pasar Modal. Edisi Kelima. Yogyakarta: UPP STIM YKPNSunariyah, 2006. Pengantar Pengetahuan Pasar Modal. Edisi Kelima. Yogyakarta: UPP STIM YKPN

Tandelilin, Eduardus. 2010. Portofolio dan Investasi Teori dan Aplikasi. Edisi Pertama. Yogyakarta: KANISIUS

Widoatmodjo, Sawidji. 2015. Pengetahuan Pasar Modal untuk Konteks Indonesia. Jakarta: Kompas Gramedia

Wira, Desmond. 2014. Analisis Fundamenal Saham Edisi Kedua. Jakarta: Penerbit Exceed Books

Muttaqim, H. (2013). ANALISIS VALUASI SAHAM PT. ADHI KARYA (PERSERO) TBK DENGAN METODE DISCOUNTED CASH FLOW (DCF). Economic Management \& Bussiness, 14(4)

Malinda, S.,\& Wahab,Z. (2015). STOCK VALUATION AND BUSSINESS PROSPECT OF PT PERUSAHAAN NEGARA (PERSERO), TBK

Khasanah, Nur. (2012). PENILAIAN HARGA SAHAM DENGAN DISCOUNTED MODEL DAN FREE CASH FLOW TO
EQUITY (Studi pada Indeks Saham LQ45 di Bursa Efek Jakarta periode 2007-2011)

Ranodya, B. G., \& Norita. (2016) ANALISIS HARGA WAJAR SAHAM DENGAN MENGGUNAKAN METODE DIVIDEND DISCOUNT MODEL (DDM) DAN PRICE EARNING RATIO (PER) UNTUK PENGAMBILAN KEPUTUSAN BUY, HOLD, SELL (Studi Kasus Pada Saham Perusahaan yang berada Pada Indeks LQ45 Periode 2014). $\mathrm{e}^{-}$ Proceeding of Management : Vol.3, No.2 Agustus 2016, hlm. 1187-1196

Sukmawati, E. E., \& AR, M. D. (2013). ANALISIS FUNDAMENTAL DENGAN PENDEKATAN PRICE EARNING RATIO (PER) UNTUK MENILAI KEWAJARAN HARGA SAHAM DAN KEPUTUSAN INVESTASI (Studi Pada Perusahaan Kosmetik dan Barang Keperluan Rumah Tangga yang Listing Di Bursa Efek Indonesia Periode 2009-2011). Jurnal Administrasi Bisnis, 2(2), 21-29.

https://www.indonesiainvestments.com/id/bisnis/kolom -bisnis/penjualan-semen-diindonesia-jatuh-drastisharapan-pada-proyekinfrastruktur/item5651

http://www.globalcement.com/magazin e/articles/964-preview-the-top100-global-cement-companiesand-global-per-capita-capacitytrends

http://industri.bisnis.com/read/201611 11/257/601719/ekspor-semenindonesia-diproyeksi-tembus-2juta-ton

http://industri.kontan.co.id/news/seme $\mathrm{n}$-indonesia-jaga-pangsa-pasarsemen 
JURNAL AKTUAL AKUNTANSI KEUANGAN BISNIS TERAPAN /VOL. 1, NO 2, NOVEMBER 2018

https://www.indonesia-

investments.com/id/news/todays-

headlines/cement-sales-

indonesia-fell-in-first-half-2017-

exports-rise/item 7990

https://idx.co.id/

http://www.semenindonesia.com 